\title{
Fuzzy Analogical Gates Approach for Heat Integrated Distillation Systems
}

\author{
M. H. Hussein \\ Assistant Professor \\ Chemical \& Petroleum Refining Engineering \\ High Institute of Engineering \\ Shorouk Academy
}

\author{
Heba A. A. Gawad \\ Senior Teaching Assistant \\ Chemical \& Petroleum Refining Engineering \\ High Institute of Engineering \\ Shorouk Academy
}

\begin{abstract}
In this paper a new systematic method for optimal synthesis of heat integrated distillation column has been developed, the proposed method which is fuzzy analogical gates consists of three sequential steps to select the best separation sequence: estimation of the normalized variables parameters, Fuzzy analogical gates and selection of the best split, Two analogical gates (symmetric and asymmetric) are employed. The symmetric gate (AND gate) inputs are the normalized heat load, normalized column temperature difference. The asymmetric gate (Invoke gate) inputs are the output of the AND gate and the normalized (Q. $\Delta \mathrm{T})$. The method has been tested for three problems reported in the literature which have been solved previously using other approaches.
\end{abstract}

\section{Keywords}

Heat Integration, Fuzzy Analogical Gates, Energy saving, Distillation columns, Heat Recovery, Process Synthesis.

\section{INTRODUCTION}

In the chemical industries, the task of separation is a very energy consuming process, where distillation is the process most widely used for fluid separations. With rising energy awareness and growing environmental concerns there is a need to reduce the energy use in industry. Distillation systems consume large amounts of energy to achieve separation. In view of increasing energy costs, it is important to design distillation systems which consume less energy. Several authors have described intuitive schemes minimizing energy consumption in multicomponent distillation processes, for example, King [1], Petlyuk et al. [2], Stupin and Lockhart [3]. In a recent paper, Rathore et al. [4] described a strategy for synthesizing optimal separation systems with energy integration. The major drawback of this strategy is that it does not allow pressure variations in the separation subproblems to achieve energy integration. It is found that many more energy matches become possible when pressure variation is allowed. More specifically, for distillation systems, pressure is an important operating and design parameter that determines both the ease of separation and the level of energy integration.

An energy savings should have an impact on the overall plant energy consumption. A drastic reduction in heating demand in a distillation train can be achieved by upgrading the heat flow recovered from condensers and using it to meet process energy requirements. Several synthesis techniques have been published for finding the separation strategy, the column pressures and the heat exchanger network structure that minimize utility needs in a distillation train. These generally use two approaches, namely thermodynamic and algorithmic methods. In addition, several rules of thumb for making a quick selection of a good separation strategy have been known for years Rudd \& Powers [6]

The use of heat integration combined with complex configurations for distillation columns holds a great promise of energy savings up to about $70 \%$. In addition to saving energy, accompanied by reduced environmental impact and site utility costs, there is also a possibility for reduction in capital costs. The classical design of a multicomponent distillation plant only involves simple columns: each simple column in a multicomponent distillation configuration receives a feed and performs a sharp separation between two components of the feed mixture.

The calculation of the heat integration cost depend on using the hot product as heating medium (instead of regular reboiler) from one of the column in heating the bottom of another column (instead of regular condenser). In this case there is no cooling system and the cooled stream return as reflux to the main column from which it was taken, in this case there is no need for the condenser and there is no superheated steam for the reboiler.

In this paper a new method for optimal synthesis of heat integrated distillation column has been presented, the proposed method consists of three sequential steps to select the best separation sequence, the results of case studies show that Fuzzy analogical gates strategy is both robust and accurate in decision making while there are large possibilities in separation sequence and it's hard to decide which one is the optimum. in comparison with previous works, which ensures its economic effectiveness.

\section{PROBLEM STATEMENT}

This study is restricted to separation by ordinary distillation. Every distillation column represents an energy sink (reboiler) and energy source (condenser). If sinks and sources in a sequence are combined appropriately, a significant energy savings can be achieved. It is refer to this combination as energy integration or column matching.

The following problem is the subject of this study: "Given a single Multi-component feed stream of known conditions, (i.e. flow rate, composition, temperature and pressure), which is to be separated into pure components", find the sequence of distillation column, the energy integration, the design specifications and the operating conditions which minimize the total cost.

To reduce the complexity of the synthesis algorithm and simplify the solution space for the synthesis procedure, in this study the following assumptions are made Rathore et al. [5]: 
1. Each distillation column performs a simple split (i.e. one feed and two products):

2. Energy matches occur only between boiling and condensing streams.

3. The energy match is considered between the reboiling stream (energy sink) and the condensing stream (energy source). Minimum approach temperature $(\Delta \mathrm{T} \mathrm{min})$ is held constant at $2.5 \mathrm{~K}$.

4. Each column operates at high recovery.

5. The volatility order does not change with changes in pressure.

6. The cost of changing the temperature and pressure of streams as they pass between columns is negligible compared to column capital and energy costs.

7. No matches occur with streams outside of the distillation system.

8. No vapor recompression is used.

\section{RULES OF THUMB AND HEURISTIC ALGORITHM}

From analyzing the profit of heat integration Meszaros and Fonyo, [7], it can be observed that the column temperature difference and column heat load have an outstanding effect on profitability. Considering these properties the following rules of thumb can be formulated:

Rule1: Favour heat matches of additional heating requirement. Those matches should be preferred where the heat load of the source column (which boils the sink column) is less than the heat load of the sink column.

Rule2: Avoid the use of high-temperature utility. In order to avoid the application of an unusually high temperature utility required by a high-pressure source column it is expedient to strive for a distillation system with a more even temperature profile.

Rule3: Favour matches with maximum heat exchange. Respecting rule 1 the match with a better connection is more advantageous: when several columns can be considered as a candidate for heating a sink column, the match demanding the least additional heating of the sink column is selected.

\section{FUZZY ANALOGICAL GATES STRATEGY}

Based on the strategy of Fuzzy analogical gate S.Aly [8] the following algorithm was developed to select a small number of nearly optimal heat-integrated distillation structures and it consists of four steps:

Step1 Reject candidate matches for heat integration where the heat load of the source column is larger than that of the sink column.

Step2 Do not match the columns with the greatest temperature differences; select the match or matches with the largest heat load for the source column (s). When several schemes with the same value of the source column heat load are available and only one match is involved, prefer the column with the smallest temperature difference as the heat sink. When the schemes include distinct paired columns, prefer the scheme involving the lowest value of the highest total match temperature difference.
Step3 Repeat step 2 for the remaining candidate schemes.

Step4 Fuzzy analogical gates strategy

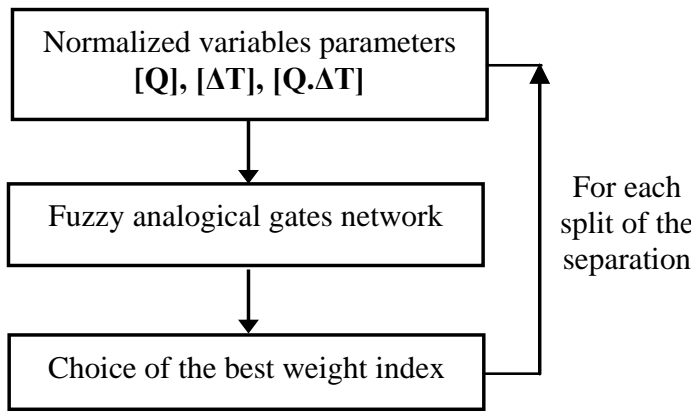

Fig.1. Fuzzy Analogical Gates Strategy

The algorithm which is followed in this step is to select the best separation sequence which consists of three sequential steps: estimation of the normalized variables parameters, Fuzzy analogical gates and selection of the best split, as shown in Fig. 1. Most of the previous work shows that the synthesis of separation mostly depends on the heat load, column temperature difference, and (Q. $\Delta \mathrm{T})$. Accordingly, in this work these three variables have been selected as inputs to the different fuzzy analogical gates.

\subsection{Fuzzy Analogical Gates Network}

Two fuzzy analogical gates will be used sequentially as shown in Fig.2 Hussein [9]. The first gate is selected to be symmetric and the second gate is asymmetric. A fuzzy analogical - AND gate will be followed by a fuzzy invoke gate.

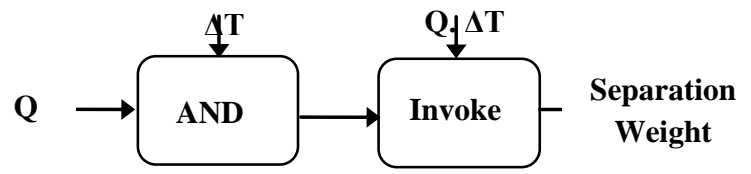

Fig.2. Fuzzy Analogical Gates Network

As shown in Fig. 2, which is analogical gates network consists of two analogical gates (symmetric and asymmetric). The symmetric gate inputs are the normalized heat load $(\mathrm{Q})$ and the normalized temperature difference $(\Delta \mathrm{T})$. The asymmetric gate inputs are the output of the symmetric gate and $(\mathrm{Q} . \Delta \mathrm{T})$. for each value of $[\mathrm{Q}, \Delta \mathrm{T}$ and $\mathrm{Q} . \Delta \mathrm{T}]$ can be derived by application of a linear programming code, two bounds $(\boldsymbol{f})_{\text {min }}$ $\&(\boldsymbol{f})_{\max }$ can be computed, and the normalized variables can be estimated by

$$
\begin{aligned}
& \mu=\frac{\left(f-f_{\text {max }}\right)}{\left(f_{\text {min }}-f_{\text {max }}\right)}, \text { Where } \\
& \mu=0 \text { If } f=f_{\text {max }} ; \mu=1 \text { If } f=f_{\text {min }}
\end{aligned}
$$

\subsection{Choice of the Best Separation Weight}

The final step corresponds to the choice of the best separation weight. The operation is carried out by comparing (S.W) values for all minimum approach temperature and by choosing the greatest one. 
$\mathrm{S} . \mathrm{W}_{\text {optimum }}=\max \left\{\mathrm{S} . \mathrm{W}_{1}, \mathrm{~S} . \mathrm{W}_{2}, \mathrm{~S} . \mathrm{W}_{3} \ldots \ldots\right\}$

\section{EXAMPLES}

The proposed method will be tested using three case studies reported in the literature, for comparison.

\subsection{Example 1: Separation of a 5 component mixture}

This example was discussed first by Heaven [10], then (Perry and Chilton, [11]; Rathore et al., [4 and 5]; Freshwater and Ziogou [12]. The feed stream is $907.2 \mathrm{by} \mathrm{mol} / \mathrm{hr}$, composed of five light hydrocarbons shown in Table 1; to be separated into essentially pure components (98\% recovery for both keys in all columns). The best sequence without heat integration is [A/BCDE, BC/DE, B/C, D/E] according to Heaven (1969). Stream data are given in Table 1, the optimal parameters of distillation columns according to Rathore et al. [4 and 5], Morari and Faith [13] are shown in Table 2. All feasible matches for the sequences $[\mathrm{A} / \mathrm{BCDE}, \mathrm{BC} / \mathrm{DE}, \mathrm{B} / \mathrm{C}, \mathrm{D} / \mathrm{E}]$ are summarized in the Matrix Integration in Table 3. Fuzzy analogical gates inputs and Fuzzy Analogical gates results are shown in Table 4 and 5. Figure 3 shows the final flow sheet of the integrated system with two columns

\subsection{Example 2: Separation of a 6 component mixture}

This example consists of six component feed stream that has to be separated into six-component products by sharp separators; Table 7 reports the main data for the feed flow rate; Towers cost are given in Table 8 Hussein [14], The characteristics of separation subproblems for the mixture $[\mathrm{ABCDEF}]$ are given in Table 9.

The best sequence without heat integration is $[\mathrm{AB} / \mathrm{CDEF}$, $\mathrm{CD} / \mathrm{EF}, \mathrm{A} / \mathrm{B}, \mathrm{C} / \mathrm{D}, \mathrm{E} / \mathrm{F}$ ] with total annual cost of US\$ $2,507,833.23$. All feasible matches are summarized in the matrix Integration in Table 10. Fuzzy analogical gates inputs and results are shown in Table 11 and 12. The total annual cost with heat integration is equal to US $\$ 2,163,833$ which gives $13.72 \%$ reduction in cost compared with separation sequence without heat integration. Figure 4 shows the final flow sheet of the integrated system with four columns.

\subsection{Example 3: Separation of a 7 component mixture}

This example consists of seven component feed stream with feed flowrate of $1600 \mathrm{Kmol} / \mathrm{hr}$ that has to be separated into seven component products by sharp separators; Table 13, reports the main data for the feed flow rate. The characteristics of separation subproblems for the mixture $[\mathrm{ABCDEFH}]$ are given in Table 14 . The best sequence without heat integration is $[\mathrm{AB} / \mathrm{CDEFH}, \mathrm{CD} / \mathrm{EFH}, \mathrm{A} / \mathrm{B}, \mathrm{C} / \mathrm{D}$, $\mathrm{EF} / \mathrm{H}, \mathrm{E} / \mathrm{F}]$, with total annual cost of US\$ 6,589,980.56. All feasible matches are summarized in the matrix Integration in Table 15. Fuzzy analogical gates inputs and results are shown in Table 16 and 17. The total annual cost with heat integration is equal to US $\$ 5,981,725.35$, which gives $9.23 \%$ reduction in cost compared with the separation sequence without heat integration. Figure 5 shows the final flow sheet of the integrated system with four columns.
Table 1: Stream data for Example 1

\begin{tabular}{cc}
\hline Component & Flowrate (mol/h) \\
\hline A: Propane & 45.4 \\
B: Iso-Butane & 136.1 \\
C: N-Butane & 226.8 \\
D: Iso-Pentane & 181.4 \\
E: N-Pentane & 317.5
\end{tabular}

Table 2: Optimal parameters of distillation columns in example according to Morari and Faith (1980) and Rathore et al., (1974)

\begin{tabular}{cccc}
\hline Column & $\begin{array}{c}\text { Heat Load } \\
\text { (MMkcal/hr) }\end{array}$ & $\begin{array}{c}\text { Column temp. } \\
\text { difference }(\mathbf{K})\end{array}$ & $\begin{array}{c}\text { Total } \\
\text { annual cost } \\
\mathbf{( \$ / y r )}\end{array}$ \\
\hline A/BCDE & 6.490 & 64.72 & 36,490 \\
BC/DE & 18.88 & 44.75 & 77,570 \\
B/C & 23.90 & 12.72 & 83,400 \\
D/E & 49.27 & 11.52 & 156,800 \\
\hline
\end{tabular}

Table 3: Matrix Integration for Example 1

\begin{tabular}{ccccc}
\hline \multicolumn{5}{c}{ Sink column } \\
\hline Source column & A/BCDE & BC/DE & D/E & B/C \\
\hline A/BCDE & & $\mathrm{R} 2$ & & \\
BC/DE & $\mathrm{R} 1$ & & & \\
D/E & $\mathrm{R} 1$ & $\mathrm{R} 1$ & & $\mathrm{R} 1$ \\
B/C & $\mathrm{R} 1$ & $\mathrm{R} 1$ & & \\
\hline
\end{tabular}

Step1. All feasible matches for the separation train [A/BCDE, BC/DE, B/C, D/E] which provides the best heatintegrated scheme according to Morrari [13] are summarized in table 2 . The matches indicated by $\mathrm{R} 1$ are rejected because of rule 1 .

Step2. The match of columns A/BCDE and BC/DE is indicated by $\mathrm{R} 2$ is rejected because of their great temperature difference. From the first two steps $60 \%$ of the feasible matches could be rejected.

From the matrix of heat integration, we have the following schemes:

- Scheme 1: $[\mathrm{D} / \mathrm{E}-\mathrm{A} / \mathrm{BCDE}][\mathrm{B} / \mathrm{C}-\mathrm{BC} / \mathrm{DE}]$;

- Scheme 2: $[\mathrm{D} / \mathrm{E}-\mathrm{BC} / \mathrm{DE}][\mathrm{B} / \mathrm{C}-\mathrm{A} / \mathrm{BCDE}]$;

- Scheme 3: $[\mathrm{D} / \mathrm{E}-\mathrm{B} / \mathrm{C}] ; \mathrm{A} / \mathrm{BCDE}, \mathrm{BC} / \mathrm{DE}$.

Fuzzy analogical gates inputs parameters $(\mathrm{Q}, \Delta \mathrm{T}$ and $\mathrm{Q} . \Delta \mathrm{T})$ for different schemes are given in Table 4.

Step3. Two separation scheme provide the largest heat load of the source column with $25.37 \mathrm{Kcal} / \mathrm{hr}$, [D/E - A/BCDE] [B/C $-\mathrm{BC} / \mathrm{DE}]$ and $[\mathrm{D} / \mathrm{E}-\mathrm{BC} / \mathrm{DE}][\mathrm{B} / \mathrm{C}-\mathrm{A} / \mathrm{BCDE}]$.The former scheme includes total match temperature differences 76.24 and $57.47 \mathrm{~K}$, while the latter scheme contains differences of 77.44 and $56.27 \mathrm{~K}$ as shown in Table 4. Since from the highest values of the total temperature difference in the schemes $(76.24$ and $77.44 \mathrm{~K})$, the match [D/E - A/BCDE] with 76.24 has the lowest value, the former (scheme 1) is preferred. 
Table 4: Fuzzy analogical gates inputs for Example 1

\begin{tabular}{cccc}
\hline $\begin{array}{c}\text { Distillation } \\
\text { schemes }\end{array}$ & $\begin{array}{c}\mathbf{Q \times 1 0} \\
(\mathbf{k c a l} / \mathbf{h r})\end{array}$ & $\begin{array}{c}\mathbf{\Delta T} \\
(\mathbf{K})\end{array}$ & $\begin{array}{c}\mathbf{Q . \Delta T} \mathbf{\Delta ~ 1 0} \\
(\mathbf{K c a l ~ K} / \mathbf{h r})\end{array}$ \\
\hline Scheme 1 & 25.37 & {$[76.24,57.47]$} & {$[987.6,1148.8]$} \\
Scheme 2 & 25.37 & {$[56.27,77.44]$} & {$[1412,724.04]$} \\
Scheme 3 & 23.90 & {$[12.72]$} & {$[871.59]$} \\
\hline
\end{tabular}

Step4. The scheme with the next largest heat load of the source column is $[\mathrm{D} / \mathrm{E}-\mathrm{B} / \mathrm{C}]$; $\mathrm{A} / \mathrm{BCDE}, \mathrm{BC} / \mathrm{DE}$ including a $23.90 \mathrm{Kcal} / \mathrm{hr}$ heat load.

The output of the analogical invoke gate is the separation weight and by comparing the results for all possible schemes. Scheme 1 is selected thus; yields the greatest value (1.00). The same procedure is then applied for the other schemes.

The Fuzzy Analogical gates results of the proposed method is shown in Table 5 , thus the resulting sequence is

- Scheme 1: $[D / E-A / B C D E][B / C-B C / D E]$

Table 5: Fuzzy Analogical gates results for Example 1

\begin{tabular}{ccccc}
\hline schemes & $\boldsymbol{\mu}_{\mathbf{1}}$ & $\boldsymbol{\mu}_{\mathbf{2}}$ & $\boldsymbol{\mu}_{\mathbf{3}}$ & $\mathbf{S . W}$ \\
\hline $\mathbf{1}$ & $\mathbf{1 . 0 0 0}$ & $\mathbf{0 . 9 8 4}$ & $\mathbf{1 . 0 0 0}$ & $\mathbf{1 . 0 0 0}$ \\
2 & 1.000 & 1.000 & 0.733 & 0.997 \\
3 & 0.942 & 0.164 & 0.882 & 0.037 \\
\hline
\end{tabular}

A comparison for different approach according to Morari and Faith [13], Meszaros and Fonyo [8] and the proposed method is shown in Table 6 .

Table 6: Best heat integrated structures for the separation sequence [A/BCDE, BC/DE, B/C, D/E] with two columns matches in example for different approach

\begin{tabular}{lccc}
\hline & $\begin{array}{c}\text { Morariand } \\
\text { Faith } \\
{[\mathbf{1 3}]}\end{array}$ & $\begin{array}{c}\text { Meszaros } \\
\text { and Fonyo } \\
{[8]}\end{array}$ & $\begin{array}{c}\text { Fuzzy } \\
\text { Analogical } \\
\text { Gates }\end{array}$ \\
\hline Scheme & TAC $(\mathbf{\$} / \mathbf{y r})$ & $\mathbf{\Delta T}$ & S.W \\
\hline Scheme 1 & $\mathbf{3 1 2 , 2 5 0}$ & $\mathbf{7 6 . 2 4}$ & $\mathbf{1 . 0 0 0}$ \\
Scheme 2 & 312,480 & 77.44 & 0.997 \\
Scheme 3 & - & - & 0.037 \\
\hline
\end{tabular}

Table 7: Stream data for Example 2

\begin{tabular}{|c|c|c|c|}
\hline Component & $\begin{array}{c}\text { Flowrate } \\
(\mathbf{k m o l} / \mathbf{h})\end{array}$ & $\begin{array}{c}\text { Boiling point } \\
\text { temperature } \\
(\mathrm{K}) \\
\end{array}$ & $\begin{array}{c}\text { Relative } \\
\text { Volatility } \\
(\alpha) \\
\end{array}$ \\
\hline \multirow[t]{2}{*}{ A: Propylene } & 96.0 & 225.4 & \\
\hline & & & 1.208 \\
\hline \multirow[t]{2}{*}{ B: Propane } & 96.0 & 231.1 & \\
\hline & & & 2.351 \\
\hline \multirow[t]{2}{*}{ C: Iso-Butane } & 383.3 & 261.3 & \\
\hline & & & 1.067 \\
\hline \multirow[t]{2}{*}{ D: N-Butane } & 192.7 & 272.7 & \\
\hline & & & 3.000 \\
\hline \multirow[t]{2}{*}{ E: Iso-Pentane } & 239.1 & 300.8 & \\
\hline & & & 1.037 \\
\hline F: N-Pentane & 192.9 & 309.0 & \\
\hline
\end{tabular}

Table 8: Towers Cost of Example 2

\begin{tabular}{cc}
\hline Column & $\begin{array}{c}\text { Total annual cost } \\
(\$ / \mathbf{y r})\end{array}$ \\
\hline $\mathbf{A B} / \mathbf{C D E F}$ & 482,000 \\
$\mathbf{C D} / \mathbf{E F}$ & 558,000 \\
$\mathbf{A} / \mathbf{B}$ & 344,000 \\
$\mathbf{C} / \mathbf{D}$ & 489,000 \\
$\mathbf{E} / \mathbf{F}$ & 634,000 \\
\hline
\end{tabular}

Table 9: Characteristics of separation Example 2

\begin{tabular}{|c|c|c|c|c|c|c|}
\hline 䏤 & 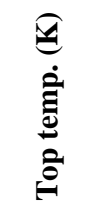 & 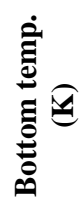 & 竘 & 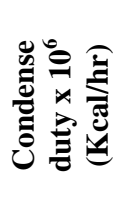 & 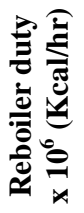 & $\begin{array}{l}4 \\
y\end{array}$ \\
\hline AB/CDEF & 267.8 & 474.0 & 3.34 & 2.50 & 4.73 & 206. \\
\hline $\mathrm{CD} / \mathrm{EF}$ & 315.7 & 497.7 & 2.18 & 6.10 & 10.1 & 182.0 \\
\hline $\mathbf{A} / \mathbf{B}$ & 316.0 & 346.0 & 3.54 & 4.81 & 5.32 & 30 \\
\hline C/D & 321.3 & 364.9 & 2.28 & 9.87 & 11.3 & 43.6 \\
\hline E/F & 320.7 & 345.1 & 1.38 & 11.1 & 12.1 & 24.4 \\
\hline
\end{tabular}

Table 10: Matrix Integration Example 2

\begin{tabular}{|c|c|c|c|c|c|}
\hline \multicolumn{6}{|c|}{ Sink column } \\
\hline 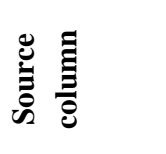 & 空 & 空 & $\sum$ & తి & 国 \\
\hline AB/CDEF & & $\mathrm{R} 2$ & & & \\
\hline $\mathrm{CD} / \mathrm{EF}$ & $\mathrm{R} 1$ & & R1 & & \\
\hline $\mathbf{A} / \mathbf{B}$ & $\mathrm{R} 1$ & & & & \\
\hline C/D & $\mathrm{R} 1$ & $\mathrm{R} 1$ & $\mathrm{R} 1$ & & \\
\hline $\mathbf{E} / \mathbf{F}$ & $\mathrm{R} 1$ & $\mathrm{R} 1$ & $\mathrm{R} 1$ & R1 & \\
\hline
\end{tabular}

From the matrix of heat integration, we have the following schemes:

- Scheme 1: $[\mathrm{CD} / \mathrm{EF}-\mathrm{A} / \mathrm{B}][\mathrm{C} / \mathrm{D}-\mathrm{AB} / \mathrm{CDEF}]$; $\mathrm{E} / \mathrm{F}$

- Scheme 2: $[\mathrm{CD} / \mathrm{EF}-\mathrm{A} / \mathrm{B}][\mathrm{E} / \mathrm{F}-\mathrm{AB} / \mathrm{CDEF}]$; $\mathrm{C} / \mathrm{D}$

- $\quad$ Scheme 3: $[\mathrm{A} / \mathrm{B}-\mathrm{AB} / \mathrm{CDEF}][\mathrm{C} / \mathrm{D}-\mathrm{CD} / \mathrm{EF}]$; $\mathrm{E} / \mathrm{F}$

- $\quad$ Scheme 4: $[\mathrm{A} / \mathrm{B}-\mathrm{AB} / \mathrm{CDEF}][\mathrm{E} / \mathrm{F}-\mathrm{CD} / \mathrm{EF}]$; $\mathrm{C} / \mathrm{D}$

- Scheme 5: $[\mathrm{A} / \mathrm{B}-\mathrm{AB} / \mathrm{CDEF}][\mathrm{E} / \mathrm{F}-\mathrm{C} / \mathrm{D}]$; $\mathrm{CD} / \mathrm{EF}$

- $\quad$ Scheme 6: $[\mathrm{C} / \mathrm{D}-\mathrm{AB} / \mathrm{CDEF}][\mathrm{E} / \mathrm{F}-\mathrm{CD} / \mathrm{EF}]$; $\mathrm{A} / \mathrm{B}$

- Scheme 7: $[\mathrm{C} / \mathrm{D}-\mathrm{AB} / \mathrm{CDEF}][\mathrm{E} / \mathrm{F}-\mathrm{A} / \mathrm{B}]$; $\mathrm{CD} / \mathrm{EF}$

- Scheme 8: [C/D - CD/EF] $[\mathrm{E} / \mathrm{F}-\mathrm{AB} / \mathrm{CDEF}]$ $\mathrm{A} / \mathrm{B}$

- Scheme 9: $[\mathrm{C} / \mathrm{D}-\mathrm{CD} / \mathrm{EF}][\mathrm{E} / \mathrm{F}-\mathrm{A} / \mathrm{B}]$; $\mathrm{AB} / \mathrm{CDEF}$ 
- Scheme 10: $[\mathrm{C} / \mathrm{D}-\mathrm{A} / \mathrm{B}][\mathrm{E} / \mathrm{F}-\mathrm{AB} / \mathrm{CDEF}]$; $\mathrm{CD} / \mathrm{EF}$

- Scheme 11: $[\mathrm{C} / \mathrm{D}-\mathrm{A} / \mathrm{B}][\mathrm{E} / \mathrm{F}-\mathrm{CD} / \mathrm{EF}]$; $\mathrm{AB} / \mathrm{CDEF}$

- Scheme 12: [E/F - C/D] [CD/EF - A/B]; $\mathrm{AB} / \mathrm{CDEF}$

The results of Fuzzy analogical gates inputs parameters $(\mathrm{Q}$, $\Delta \mathrm{T}$ and $\mathrm{Q} . \Delta \mathrm{T}$ ) for different schemes are given in Table 11.

Table 11: Fuzzy analogical gates inputs for Example 2

\begin{tabular}{cclc}
\hline $\begin{array}{c}\text { Distillation } \\
\text { schemes }\end{array}$ & $\begin{array}{c}\mathbf{Q ~ x 1 0} \\
(\mathbf{k c a l} / \mathbf{h r})\end{array}$ & \multicolumn{1}{|c}{$\mathbf{\Delta T}(\mathbf{K})$} & $\begin{array}{c}\mathbf{Q . \Delta T} \mathbf{~ \mathbf { ~ 1 0 }} \\
\mathbf{( K c a l ~ K / h r})\end{array}$ \\
\hline $\mathbf{1}$ & 10.05 & {$[212,249.8]$} & {$[1997.8,1468.1]$} \\
$\mathbf{2}$ & 10.05 & {$[212,230.6]$} & {$[1997.8,1270.5]$} \\
$\mathbf{3}$ & 14.83 & {$[236.2,225.6]$} & {$[1134.9,2330.8]$} \\
$\mathbf{4}$ & 14.83 & {$[236.2,206.4]$} & {$[1134.9,2133.4]$} \\
$\mathbf{5}$ & 16.03 & {$[236.2,68]$} & {$[1134.9,787.9]$} \\
$\mathbf{6}$ & 14.83 & {$[249.8,206.4]$} & {$[1468.1,2133.4]$} \\
$\mathbf{7}$ & 10.05 & {$[249.8,54.4]$} & {$[1468.1,454.8]$} \\
$\mathbf{8}$ & 14.83 & {$[225.6,230.6]$} & {$[2133.4,1270.5]$} \\
$\mathbf{9}$ & 15.42 & {$[225.6,54.4]$} & {$[2133.4,454.8]$} \\
$\mathbf{1 0}$ & 10.05 & {$[73.6,230.6]$} & {$[652.2,1270.5]$} \\
$\mathbf{1 1}$ & 15.42 & {$[73.6,206.4]$} & {$[652.2,2133.4]$} \\
$\mathbf{1 2}$ & 16.62 & {$[68,212]$} & {$[787.9,1997.8]$} \\
\hline
\end{tabular}

The Fuzzy Analogical gates results is shown in Table 12, thus the resulting sequence is

- Scheme 6: $[C / D-A B / C D E F][E / F-C D / E F] ; A / B$

Table 12: Fuzzy Analogical gates results for Example 2

\begin{tabular}{ccccc}
\hline schemes & $\boldsymbol{\mu}_{\mathbf{1}}$ & $\boldsymbol{\mu}_{\mathbf{2}}$ & $\boldsymbol{\mu}_{\mathbf{3}}$ & $\mathbf{S . W}$ \\
\hline 1 & 0.604 & 1.000 & 1.000 & 0.714 \\
2 & 0.604 & 0.923 & 0.865 & 0.718 \\
3 & 0.892 & 0.945 & 0.773 & 0.937 \\
4 & 0.892 & 0.945 & 0.773 & 0.937 \\
5 & 0.964 & 0.945 & 0.536 & 0.920 \\
$\mathbf{6}$ & $\mathbf{0 . 8 9 2}$ & $\mathbf{1 . 0 0 0}$ & $\mathbf{1 . 0 0 0}$ & $\mathbf{1 . 0 0 0}$ \\
7 & 0.604 & 1.000 & 0.309 & 0.600 \\
8 & 0.892 & 0.923 & 0.865 & 0.952 \\
9 & 0.927 & 0.903 & 0.309 & 0.875 \\
10 & 0.604 & 0.923 & 0.444 & 0.633 \\
11 & 0.927 & 0.826 & 0.444 & 0.829 \\
12 & 1.000 & 0.848 & 0.536 & 0.872 \\
\hline
\end{tabular}

Table 13: Stream data for Example 3

\begin{tabular}{lccc}
\hline component & $\begin{array}{c}\text { Mole } \\
\text { fraction }\end{array}$ & $\begin{array}{c}\text { Boiling point } \\
\text { temperature } \\
(\mathbf{K})\end{array}$ & $\begin{array}{c}\text { Relative } \\
\text { Volatility } \\
(\boldsymbol{\alpha})\end{array}$ \\
\hline A:Propylene & 0.060 & 225.4 & \\
\hline & & & 1.236 \\
\hline B: Propane & 0.060 & 231.1 & 1.021 \\
\hline \multicolumn{3}{l}{} & \\
\hline C:Iso-Butane & 0.240 & 261.3 & 1.529 \\
\hline D:N-Butane & 0.156 & 272.7 & \\
\hline \multicolumn{3}{l}{} \\
\hline E:Iso -Pentane & 0.120 & 300.8 \\
\hline
\end{tabular}

\begin{tabular}{lccc}
\hline F: N-Pentane & 0.250 & 309.0 & \\
\hline & & & 4.152 \\
\hline H: N-Hexane & 0.120 & 341.7 & \\
\hline
\end{tabular}

The characteristics of separation subproblems for the mixture [ABCDEFH] are given in Table 14

Table 14: Characteristics of separation for Example 3

\begin{tabular}{|c|c|c|c|c|c|c|}
\hline 音 & 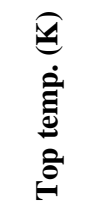 & 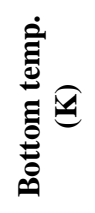 & 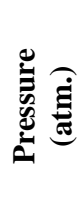 & 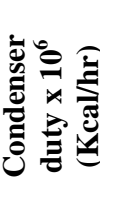 & 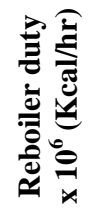 & $\underset{\frac{6}{4}}{\stackrel{8}{4}}$ \\
\hline AB/CDEFH & 265.2 & 483.5 & 3.34 & 2.53 & 4.97 & 218.3 \\
\hline CD/EFH & 309.5 & 532.8 & 2.17 & 6.21 & 11.4 & 223.3 \\
\hline EF/H & 310.8 & 426 & 1.30 & 5.01 & 7.13 & 115.2 \\
\hline $\mathbf{A} / \mathbf{B}$ & 316.1 & 346.2 & 3.54 & 4.50 & 4.99 & 30.1 \\
\hline C/D & 319.8 & 362.6 & 2.27 & 9.76 & 11.2 & 42.8 \\
\hline $\mathrm{E} / \mathrm{F}$ & 317.9 & 341 & 1.36 & 10.2 & 11.09 & 23.1 \\
\hline
\end{tabular}

All feasible matches for the sequences $[\mathrm{AB} / \mathrm{CDEF}, \mathrm{CD} / \mathrm{EF}$, $\mathrm{A} / \mathrm{B}, \mathrm{C} / \mathrm{D}, \mathrm{E} / \mathrm{F}]$ are summarized in the matrix integration shown in Table 15

Table 15: Matrix Integration for Example 3

\begin{tabular}{|c|c|c|c|c|c|c|}
\hline \multicolumn{7}{|c|}{ Sink column } \\
\hline 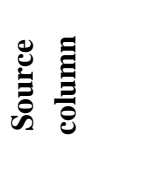 & 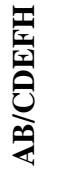 & 斑 & $\underset{\text { 空 }}{\mathbb{2}}$ & $\sum_{\downarrow}^{\infty}$ & ชิ & 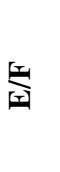 \\
\hline $\mathrm{AB} / \mathrm{CDEF}$ & & $\mathrm{R} 2$ & & & & \\
\hline CD/EFH & R1 & & $\mathrm{R} 1$ & R1 & $\mathrm{R} 1$ & $\mathrm{R} 1$ \\
\hline EF/H & $\mathrm{R} 1$ & & & $\mathrm{R} 1$ & & \\
\hline $\mathbf{A} / \mathbf{B}$ & $\mathrm{R} 1$ & & & & & \\
\hline C/D & $\mathrm{R} 1$ & & $\mathrm{R} 1$ & R1 & & $\mathrm{R} 1$ \\
\hline $\mathbf{E} / \mathbf{F}$ & $\mathrm{R} 1$ & & $\mathrm{R} 1$ & R1 & & \\
\hline
\end{tabular}

- From the matrix of heat integration, we have the following schemes:

Scheme 1: [CD/EFH - EF/H] [A/B - AB/CDEFH]; C/D; E/F Scheme 2: [CD/EFH - EF/H] [C/D - AB/CDEFH]; A/B; E/F Scheme 3: [CD/EFH - EF/H] [C/D - A/B]; AB/CDEFH; E/F Scheme 4: [CD/EFH - EF/H] [C/D - E/F]; AB/CDEFH; A/B Scheme 5: [CD/EFH - EF/H] [E/F - AB/CDEFH]; A/B; C/D Scheme 6: [CD/EFH - EF/H] [E/F - A/B]; AB/CDEFH; C/D Scheme 7: [CD/EFH - A/B] [EF/H - AB/CDEFH]; E/F; C/D Scheme 8: [CD/EFH - A/B] [C/D - EF/H]; AB/CDEFH; E/F Scheme 9: [CD/EFH - A/B] [C/D - E/F]; AB/CDEFH; EF/H Scheme 10: [CD/EFH - C/D] [EF/H - AB/CDEFH]; A/B; E/F Scheme 11: [CD/EFH - C/D] [EF/H - A/B]; AB/CDEFH; E/F Scheme 12: [CD/EFH - E/F] [EF/H -AB/CDEFH]; C/D; A/B 
Scheme 13: [CD/EFH - E/F] [EF/H - A/B]; AB/CDEFH; C/D Scheme 14: [CD/EFH - E/F] [C/D - EF/H]; AB/CDEFH; A/B Scheme 15: [A/B - AB/CDEFH] [CD/EFH - C/D]; EF/H; E/F Scheme 16: [A/B - AB/CDEFH] [CD/EFH - E/F]; EF/H; C/D Scheme 17: [C/D - AB/CDEFH] [CD/EFH - A/B]; EF/H; E/F Scheme 18: [C/D - AB/CDEFH] [EF/H - A/B]; CD/EFH; E/F Scheme 19: [C/D - AB/CDEFH] [E/F - EF/H]; CD/EFH; A/B Scheme 20: [C/D - AB/CDEFH] [E/F - A/B]; CD/EFH; EF/H Scheme 21: [C/D - EF/H] [A/B -AB/CDEFH]; CD/EFH; E/F Scheme 22: [C/D - A/B] [CD/EFH - E/F]; AB/CDEFH; EF/H Scheme 23: [C/D - A/B] [EF/H - AB/CDEFH]; CD/EFH; E/F Scheme 24: [C/D - A/B] [E/F - AB/CDEFH]; CD/EFH; EF/H Scheme 25: [C/D - A/B] [E/F - EF/H]; AB/CDEFH; CD/EFH Scheme 26: [C/D - E/F] [EF/H - AB/CDEFH]; CD/EFH; A/B Scheme 27: [C/D - E/F] [EF/H - A/B]; AB/CDEFH; CD/EFH Scheme 28: [C/D - E/F] [A/B -AB/CDEFH]; CD/EFH; EF/H Scheme 29: [E/F - AB/CDEFH] [CD/EFH - A/B]; C/D; EF/H Scheme 30: [E/F - AB/CDEFH] [CD/EFH - C/D]; EF/H; A/B Scheme 31: [E/F - AB/CDEFH] [EF/H - A/B]; CD/EFH; C/D Scheme 32: [E/F - AB/CDEFH] [C/D - EF/H]; CD/EFH; A/B Scheme 33: [E/F - EF/H] [CD/EFH - A/B]; AB/CDEFH; C/D Scheme 34: [E/F - EF/H] [CD/EFH - C/D]; AB/CDEFH; A/B Scheme 35: [E/F - EF/H] [A/B - AB/CDEFH]; CD/EFH; C/D Scheme 36: [E/F - A/B] [CD/EFH - C/D]; AB/CDEFH; EF/H Scheme 37: [E/F - A/B] [EF/H - AB/CDEFH]; C/D; CD/EFH Scheme 38: [E/F - A/B] [C/D - EF/H]; AB/CDEFH; CD/EFH The results of Fuzzy analogical gates inputs parameters (Q, $\Delta \mathrm{T}$ and $\mathrm{Q} . \Delta \mathrm{T}$ ) for different schemes are given in Table 16.

Table 16: Fuzzy analogical gates inputs for Example 3

\begin{tabular}{ccll}
\hline Scheme & $\begin{array}{c}\mathbf{Q ~ x 1 0} \\
(\mathbf{k c a l} / \mathbf{h r})\end{array}$ & \multicolumn{1}{c}{$\Delta \mathbf{T} \mathbf{( K )}$} & \multicolumn{1}{c}{$\begin{array}{c}\mathbf{Q . \Delta} \mathbf{\Delta T} \mathbf{~ 1 0} \mathbf{~}^{\mathbf{6}} \\
(\mathbf{K c a l ~ K} / \mathbf{h r})\end{array}$} \\
\hline 1 & 12.10 & {$[338.5,248.4]$} & {$[3366.9,1235.1]$} \\
2 & 12.10 & {$[338.5,261.1]$} & {$[3366.9,1564.3]$} \\
3 & 12.12 & {$[338.5,72.9]$} & {$[3366.9,629.5]$} \\
4 & 18.22 & {$[338.5,65.9]$} & {$[3366.9,735.5]$} \\
5 & 12.10 & {$[338.5,241.4]$} & {$[3366.9,1341.1]$} \\
6 & 12.12 & {$[338.5,53.2]$} & {$[3366.9,406.3]$} \\
7 & 9.960 & {$[253.4,333.5]$} & {$[2695.8,1906.3]$} \\
8 & 12.12 & {$[253.4,158]$} & {$[2695.8,1300.7]$} \\
9 & 16.08 & {$[253.4,65.9]$} & {$[2695.8,735.5]$} \\
10 & 16.17 & {$[266.1,333.5]$} & {$[3024.9,1906.3]$} \\
11 & 16.19 & {$[266.1,145.3]$} & {$[3024.9,971.5]$} \\
12 & 16.06 & {$[246.4,333.5]$} & {$[2801.7,1906.3]$} \\
13 & 16.08 & {$[246.4,145.3]$} & {$[2801.7,971.5]$} \\
14 & 18.22 & {$[246.4,158]$} & {$[2801.7,1300.7]$} \\
\hline
\end{tabular}

\begin{tabular}{cccl}
\hline Scheme & $\begin{array}{c}\mathbf{Q ~ x 1 0} \\
(\mathbf{k c a l} / \mathbf{h r})\end{array}$ & \multicolumn{1}{c}{$\boldsymbol{\Delta T} \mathbf{( K )}$} & \multicolumn{1}{c}{$\begin{array}{c}\mathbf{Q . \Delta} \mathbf{\Delta T} \mathbf{~ 1 0} \\
(\mathbf{K c a l ~ K} / \mathbf{h r})\end{array}$} \\
\hline 15 & 16.17 & {$[248.4,266.1]$} & {$[1235.1,3024.9]$} \\
16 & 16.06 & {$[248.4,246.4]$} & {$[1235.1,2801.7]$} \\
17 & 9.960 & {$[261.1,253.4]$} & {$[1564.3,2695.8]$} \\
18 & 9.960 & {$[261.1,145.3]$} & {$[1564.3,971.5]$} \\
19 & 12.10 & {$[261.1,138.3]$} & {$[1564.3,1077.5]$} \\
20 & 9.960 & {$[261.1,53.2]$} & {$[1564.3,406.3]$} \\
21 & 12.10 & {$[158,248.4]$} & {$[1300.7,1235.1]$} \\
22 & 16.08 & {$[72.9,246.4]$} & {$[629.5,2801.7]$} \\
23 & 9.960 & {$[72.9,333.5]$} & {$[629.5,1906.3]$} \\
24 & 9.960 & {$[72.9,241.4]$} & {$[629.5,1341.1]$} \\
25 & 12.12 & {$[72.9,138.3]$} & {$[629.5,1077.5]$} \\
26 & 16.06 & {$[65.9,333.5]$} & {$[735.5,1906.3]$} \\
27 & 16.08 & {$[65.9,145.3]$} & {$[735.5,971.5]$} \\
28 & 16.06 & {$[65.9,248.4]$} & {$[735.5,1235.1]$} \\
29 & 9.960 & {$[241.4,253.4]$} & {$[1341.1,2695.8]$} \\
30 & 16.17 & {$[241.4,266.1]$} & {$[1341.1,3024.9]$} \\
31 & 9.960 & {$[241.4,145.3]$} & {$[1341.1,971.5]$} \\
32 & 12.10 & {$[241.4,158]$} & {$[1341.1,1300.7]$} \\
33 & 12.12 & {$[138.3,253.4]$} & {$[1077.5,2695.8]$} \\
34 & 18.33 & {$[138.3,266.1]$} & {$[1077.5,971.5]$} \\
35 & 12.10 & {$[138.3,248.4]$} & {$[1077.5,1235.1]$} \\
36 & 16.19 & {$[53.2,266.1]$} & {$[406.3,971.5]$} \\
37 & 9.960 & {$[53.2,333.5]$} & {$[406.3,1906.3]$} \\
38 & 12.12 & {$[53.2,158]$} & {$[406.3,1300.7]$} \\
\hline
\end{tabular}

The Fuzzy Analogical gates results is shown in Table 17, thus the resulting sequence is

\section{Scheme 10:}

- $\quad[C D / E F H-C / D][E F / H-A B / C D E F H] ; A / B ; E / F$

\section{CONCLUSIONS}

Process integration does not only involve the search for the optimal design parameters, but even more important the development of the optimal processing strategy. The decision is often based on rules of thumb or on exhaustive enumeration of all the possibilities. Fuzzy analogical gate strategy has been proposed for synthesizing multicomponent separation sequences for five, six and seven components and helping for decision making when there are a large number of possibilities.

Table 17: Fuzzy Analogical gates results for Example 3

\begin{tabular}{ccccc}
\hline Sequences & $\boldsymbol{\mu}_{\mathbf{1}}$ & $\boldsymbol{\mu}_{\mathbf{2}}$ & $\boldsymbol{\mu}_{\mathbf{3}}$ & $\mathbf{S . W}$ \\
\hline 1 & 0.660 & 1.000 & 0.647 & 0.731 \\
2 & 0.660 & 1.000 & 0.820 & 0.768 \\
3 & 0.660 & 1.000 & 0.330 & 0.670 \\
4 & 0.993 & 1.000 & 0.385 & 0.951 \\
5 & 0.660 & 1.000 & 0.703 & 0.744 \\
6 & 0.660 & 1.000 & 0.213 & 0.673 \\
7 & 0.543 & 0.985 & 1.000 & 0.621 \\
8 & 0.660 & 0.748 & 0.682 & 0.733 \\
9 & 0.877 & 0.748 & 0.385 & 0.758 \\
$\mathbf{1 0}$ & $\mathbf{0 . 8 8 2}$ & $\mathbf{0 . 9 8 9}$ & $\mathbf{1 . 0 0 0}$ & $\mathbf{0 . 9 9 6}$ \\
11 & 0.883 & 0.786 & 0.509 & 0.802 \\
12 & 0.876 & 0.985 & 1.000 & 0.991 \\
13 & 0.877 & 0.727 & 0.509 & 0.760 \\
14 & 0.993 & 0.727 & 0.682 & 0.806 \\
15 & 0.882 & 0.786 & 0.647 & 0.831 \\
\hline
\end{tabular}




\begin{tabular}{lcccc}
\hline Sequences & $\boldsymbol{\mu}_{\mathbf{1}}$ & $\boldsymbol{\mu}_{\mathbf{2}}$ & $\boldsymbol{\mu}_{\mathbf{3}}$ & $\mathbf{S . W}$ \\
\hline 16 & 0.876 & 0.733 & 0.647 & 0.795 \\
17 & 0.543 & 0.771 & 0.820 & 0.656 \\
18 & 0.543 & 0.771 & 0.509 & 0.600 \\
19 & 0.660 & 0.771 & 0.565 & 0.709 \\
20 & 0.543 & 0.771 & 0.213 & 0.556 \\
21 & 0.660 & 0.773 & 0.647 & 0.729 \\
22 & 0.877 & 0.727 & 0.330 & 0.738 \\
23 & 0.543 & 0.985 & 0.330 & 0.529 \\
24 & 0.543 & 0.713 & 0.330 & 0.563 \\
25 & 0.660 & 0.408 & 0.330 & 0.429 \\
26 & 0.876 & 0.989 & 0.385 & 0.876 \\
27 & 0.877 & 0.429 & 0.385 & 0.425 \\
28 & 0.876 & 0.733 & 0.385 & 0.746 \\
29 & 0.543 & 0.748 & 0.703 & 0.642 \\
30 & 0.882 & 0.786 & 0.703 & 0.845 \\
31 & 0.543 & 0.713 & 0.509 & 0.601 \\
32 & 0.660 & 0.713 & 0.682 & 0.724 \\
33 & 0.660 & 0.748 & 0.565 & 0.705 \\
34 & 1.000 & 0.786 & 0.509 & 0.819 \\
35 & 0.660 & 0.733 & 0.565 & 0.701 \\
36 & 0.883 & 0.786 & 0.213 & 0.795 \\
37 & 0.543 & 0.985 & 0.213 & 0.519 \\
38 & 0.660 & 0.466 & 0.213 & 0.476 \\
\hline & & & &
\end{tabular}

The heat integration matrix represents all possible matches that could occur in the system with the aid of three heuristic rules for identifying the feasible matches between condenser $\&$ reboiler. It show a good percent of reduction cost compared to the total cost without heat integration, which ensures its economic effectiveness.

The proposed method have a large applications in chemical and petroleum refining engineering such as heat and mass exchanger network, waste water minimization, reactor network, yielded optimum solutions which are consistent with different approach.

\section{Nomenclature}

S.W

Separation Weight

TAC

Total Annualized Cost

$\mu_{1}$

Normalized Q

$\mu_{2}$

Normalized $\Delta \mathrm{T}$

$\mu_{3}$

Normalized Q. $\Delta \mathrm{T}$

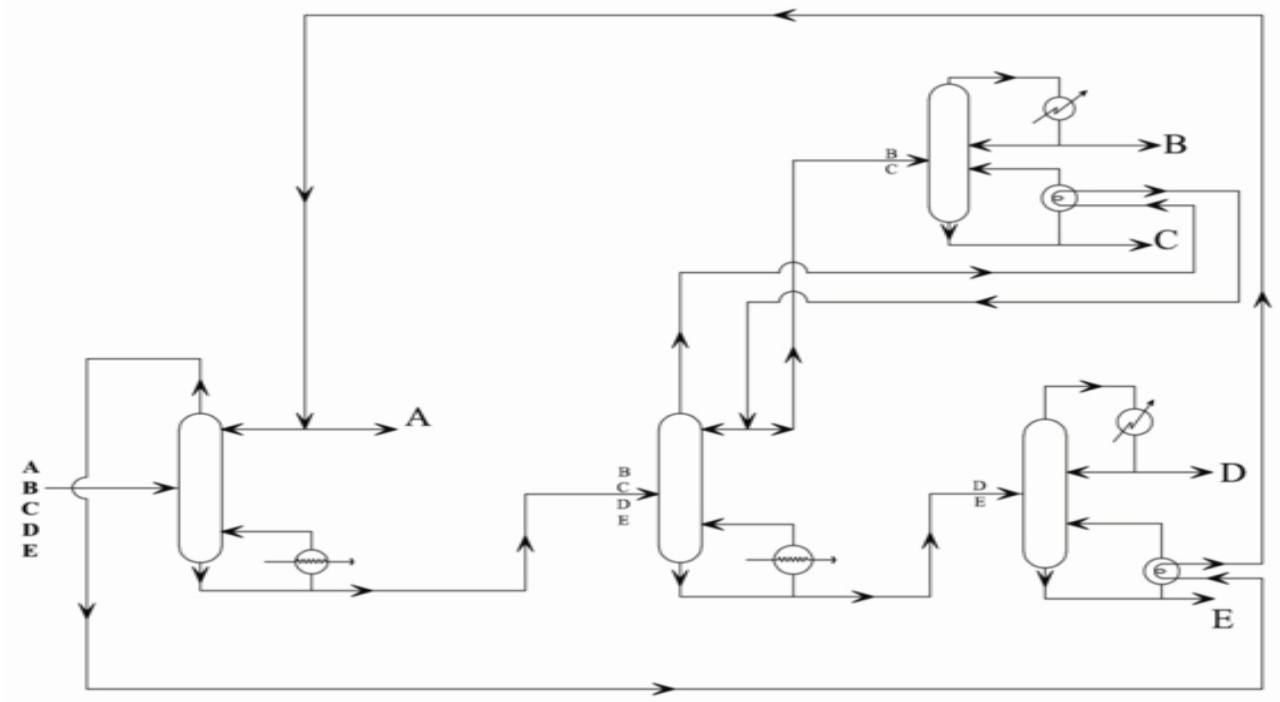

Fig.3. Flow sheet for 5-component mixture with energy integration for Example 1Scheme 1:

$[D / E-A / B C D E][B / C-B C / D E]$ 


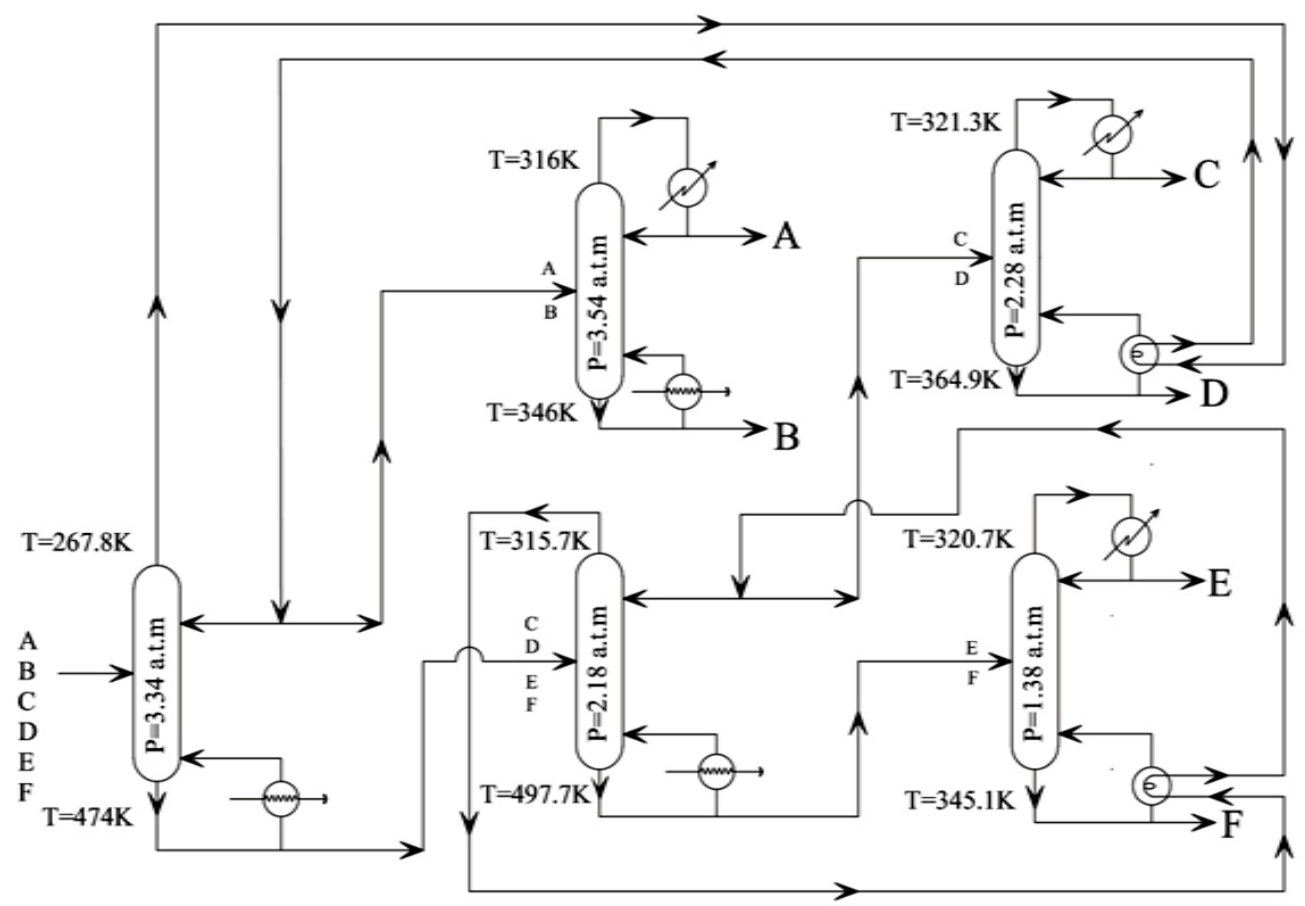

Fig.4. Flow sheet for 6-component mixture with energy integration for Example 2 Scheme 6: $[C / D-A B / C D E F][E / F-C D / E F] ; A / B$

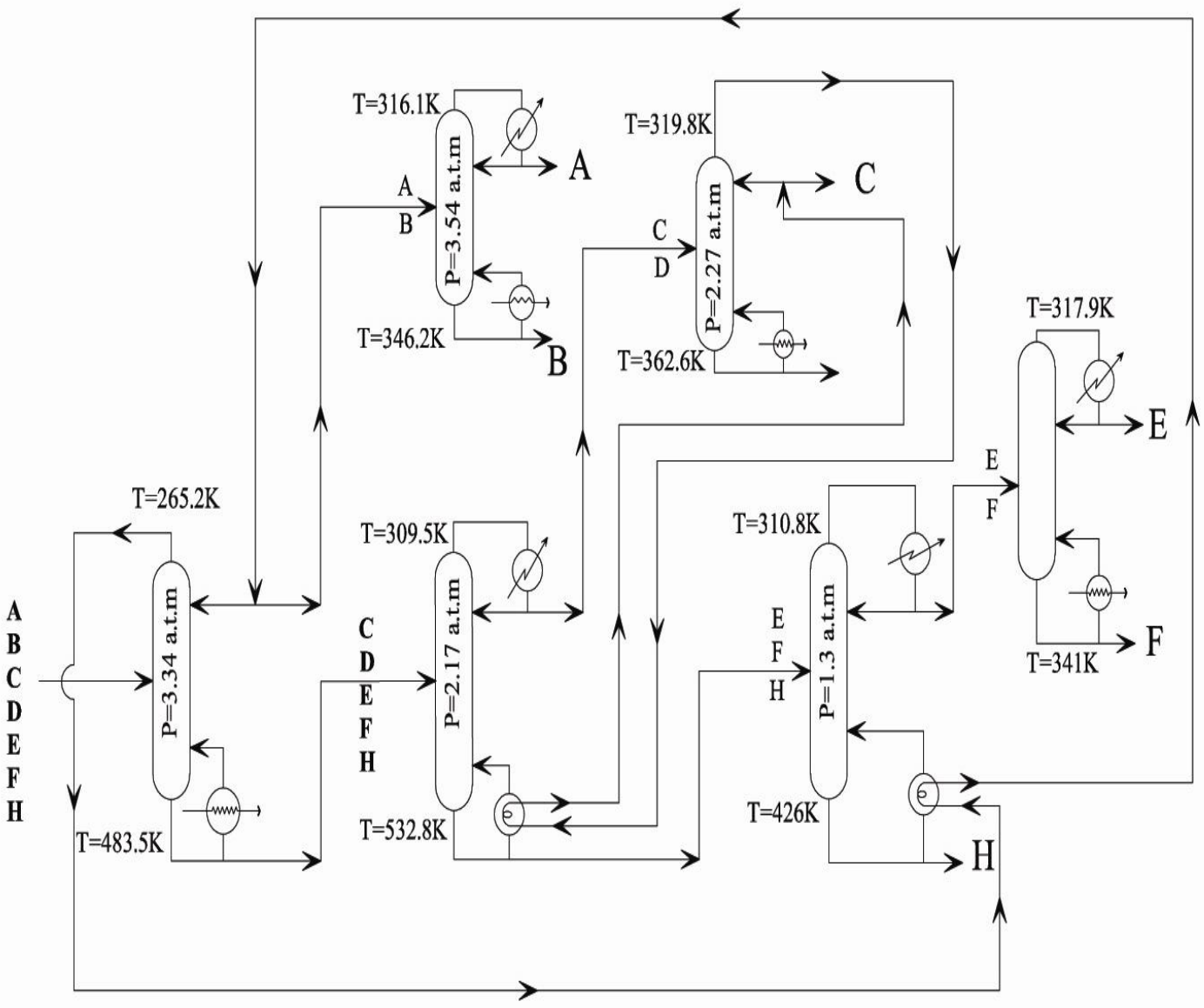

Fig.5. Flow sheet for 7-component mixture with energy integration for Example 3

$[C D / E F H-C / D][E F / H-A B / C D E F H] ; A / B ; E / F$ 


\section{REFERENCES}

[1] King, C. J., "Separation Processes," McGraw-Hill, New York (1971)

[2] Petlyuk, F. B., Platonov, V. M., and D. M. Slavinskii, "Thermodynamically optimal method for separating multicomponent mixtures," Int. Chem. Eng., 5, 555 (1965)

[3] Stupin, W. J., and F. J. Lockhart, "Thermally Coupled Distillation”, Chem. Eng. Progr. 68, (10), 71 (1972).

[4] Rathore, R.N. S., K. A. Vanwormer, and G. J. Powers, "Synthesis Strategies for Multicomponent Seqparation Systems with Energy Integration," AlChE J., 20, 491 (1974a).

[5] Rathore, R.N. S., K. A. Vanwormer, and G. J. Powers, Synthesis of Distillation Systems with Energy Integration, AlChE J. 20, 940 (1974b).

[6] Rudd \& Powers, "A heuristic method for the creation of a separation scheme", Ind. Eng. Chem. Res., Vol. 5, 255 (1973).

[7] Meszaros I. and Z. Fonyo, Parametric studies and extensive state optimization for energy integrated distillation systems, Hung. J. Ind. Chem., Vol.14 pp.203
(1986),.

[8] Aly. S, Fuzzy analogical gates for separation sequence synthesis, Chem. Eng. Proc, Vol. 36 (1997) 209-217.

[9] Hussein, M.H., Moselhy, H., Aly S., Awad, M. E. "Fuzzy Analogical Gates Approach for Heat Exchangers Networks". International Journal of Computer Applications. Vol. 73, No. (21): pp.1-8, (July 2013)

[10] Heaven D.L, "Optimum sequencing of distillation columns in multicomponent fractionation", M.Sc. Thesis, University of California Berkley. (1969).

[11] Perry, R. H., and C. H. Chilton (ed.), Chemical Engineers' Handbook, 5th ed., McGraw Hill (1973).

[12] Freshwater, D. C., and E. Ziogou, "Reducing Energy Requirements in Unit Operations", Chem. Eng. J., 11,215 (1976).

[13] Morari M., and D.C. Faith, The synthesis of distillation trains with heat integration, AIChE J. Vol. 26 (1980) 916.

[14] Hussein, M.H. " Synthesis of optimal heat integrated distillation systems" M.Sc Thesis, University of Suez (2010) 